\title{
Erratum to: Announcements and Reports
}

\author{
Redaktionsbüro/Editorial Office ${ }^{1}$
}

Published online: 17 November 2015

(C) Bundesamt für Verbraucherschutz und Lebensmittelsicherheit (BVL) 2015

\section{Erratum to: J. Verbr. Lebensm.}

\section{DOI 10.1007/s00003-015-0982-4}

The original version of this article unfortunately contained mistakes. It was corrected. doi:10.1007/s00003-015-0982-4.

\section{Redaktionsbüro/Editorial Office}

jvl@bvl.bund.de

$1 \quad$ Bundesamt für Verbraucherschutz und Lebensmittelsicherheit Dienststelle Berlin, Postfach 1102 60, 10832 Berlin, Germany 